\title{
Genetic Carrier
}

National Cancer Institute

\section{Source}

National Cancer Institute. Genetic Carrier. NCI Thesaurus. Code C111031.

An individual who carries an inheritable genetic mutation without manifestation of the associated condition. 